\title{
Public's Perception and Satisfaction on the Health Care System in Sultanate of Oman: A Cross-Sectional Study
}

\author{
Humaid Al-Kalbani ${ }^{1} \quad$ Tariq Al-Saadi ${ }^{2,3} \quad$ Ahmed Al-Kumzari ${ }^{4}$ Hassan Al-Bahrani ${ }^{4}$ \\ ${ }^{1}$ Department of Ophthalmology, Al-Buraimi Hospital, Ministry of \\ Health, Sultanate of Oman \\ 2Department of Neurosurgery, Khoula Hospital, Muscat, Sultanate \\ of Oman \\ ${ }^{3}$ Department of Neurology and Neurosurgery, Montreal \\ Address for correspondence Tariq Al-Saadi, MD, Department \\ of Neurosurgery, Khoula Hospital, Muscat, Sultanate of Oman; \\ Department of Neurology and Neurosurgery, Montreal Neurological \\ Institute-McGill University, 3801 Montreal, Canada \\ (e-mail: t.dhiyab@hotmail.com, tariq.al-saadi@mail.mcgill.ca).
} Neurological Institute-McGill University, Montreal, Canada

${ }^{4}$ Department of Pediatric, Sultan Qaboos University Hospital, Oman Medical Speciality Board, Muscat, Sultanate of Oman

\begin{abstract}
Keywords

- health care system in Oman

- population satisfaction

- public hospital

- private hospital

- treatment abroad

Objective There are no "gold standard" parameters to measure patient satisfaction regarding the health care system provided by the government. Most of the developed countries have well-structured health care systems, and they depend on patient satisfaction to evaluate and optimize performance and activities of such systems. The study was conducted to evaluate the Omani population's satisfaction toward public and private health care systems existing in the country.

Materials and Methods A cross-sectional study was conducted with a predesigned and pretested questionnaire that was sent to all regions of the Sultanate of Oman via an electronic link. The questionnaire included 22 questions divided into two sections: (1) public and private health care systems in Oman, and (2) abroad treatments.

Results The response rate of the 11 Oman's governorates was $73.9 \%$. There was an association between gender, age, marital status, and the level of education with the preference for local private hospital's treatment $(p<0.001)$. Both males $(88.1 \%)$ and females $(83.9 \%$ ) preferred to be treated by Omani doctors. The association between gender and the preference to be treated by the Omani doctors was statistically significant $(p=0.016)$. There was a significant relationship between the overall patient satisfaction regarding the treatment that they received and all of the following parameters: well-trained nurses, competency of doctors, professional behavior, and skill level of the staff. On the other hand, $88 \%$ of the participants were unhappy about appointment waiting times to be seen in the tertiary-care hospital.

Conclusion The study showed that most of the participants have preferred to be treated by Omani physicians and nurses, however, hospitals need to make operational and working changes in order to decrease the appointment waiting time, as this was found to be one of the most common reasons for population dissatisfaction.
\end{abstract}

DOI https://doi.org/ $10.1055 / \mathrm{s}-0040-1721554$ ISSN 0379-038X. (c) 2020. National Academy of Medical Sciences (India).

This is an open access article published by Thieme under the terms of the Creative Commons Attribution-NonDerivative-NonCommercial-License, permitting copying and reproduction so long as the original work is given appropriate credit. Contents may not be used for commercial purposes, or adapted, remixed, transformed or built upon. (https://creativecommons.org/licenses/by-nc-nd/4.0/).

Thieme Medical and Scientific Publishers Pvt. Ltd. A-12, 2nd Floor, Sector 2, Noida-201301 UP, India 


\section{Introduction}

In the last few years, the competition for providing the best medical services increased worldwide. ${ }^{1}$ Nowadays, patient satisfaction regarding governmental or public health care systems considered one of the best indicators for measuring the quality of health care system, as still there are no "gold standard" parameters to measure patient satisfaction. ${ }^{2}$ Patients' satisfaction is the extent to which service seekers feel happy with their health care, both inside and outside of physician/ surgeon's office. It is a measure of quality of service providers insights into various aspects of medicine, including the effectiveness of their care and the received empathy. Most of the developed countries having well-structured health care systems depend on patient satisfaction to evaluate the qualities of the provided services by their health care facilities. ${ }^{3}$ Understanding patient needs by both obtaining the service seekers feedback toward the offered services and establishing good communication between the patient and the physician, where their attitude and behavior, availability of services technology, and hospital-facilitated conveniences to the patient placed a major role in patient's satisfaction with some other minor factors. ${ }^{4}$ In 2016, the United States spent nearly $18 \%$ of its gross domestic product (GDP around 21.43 trillion U.S. dollar in 2019) on health care, whereas the next highest comparable country (Switzerland, GDP around 1566.23 billion U.S. dollar in 2019) devoted less than $13 \%$ to this category. ${ }^{5}$ Oman is considered as having one of the best health care systems in the world according to World Health Organization reports. ${ }^{6}$ However, Omani Ministry of Health (MOH) expenditures are less than 6.1\% (1816.88 million U.S. dollar) of its GDP and that is due to the availability of a good feedback mechanism for obtaining the patient satisfaction through a hotline system, where the $\mathrm{MoH}$ gives priority to evaluation of health care services and get patients' feedback. ${ }^{7}$

In the present study, a cross-sectional feedback was obtained by distributing a survey questionnaire to all Oman regions in order to get general ideas from Omani citizens about the quality of health care system and on the services offered by the health care providers all over the country.

\section{Materials and Methods}

This study was conducted through a questionnaire distributed to all regions of the Sultanate of Oman from February 12 to February 16, 2019 via an electronic link. Related studies to this research were reviewed, then questionnaire was formulated, and translated into the Arabic language. Participant's age, gender, marital status, and living region were obtained. The questionnaire included 22 questions. In addition to personal demographic information, the questionnaire also targeted information on educational status of the participants. The questionnaire has two main sections: (1) public and private health care systems in Oman, and (2) abroad treatments. Section (1) mainly consists of "yes or no" type of answers, whereas section (2) consists of "agree and disagree" type of questions. The questionnaire did not include any personal information about the participant so that they can feel assured about their privacy and answer the questions freely and honestly. All participants signed a consent prior to filing up the questionnaire. After all participants answered and completed the questions, the questionnaire forms were dispatched back to the sender's address. The received questionnaire forms were then perused, data recorded, and the percentages of each answered question were documented. The collected information was analyzed by using the SPSS program.

\section{Results and Discussion}

This study was conducted in the Sultanate of Oman in order to consider and use the results to improve service quality and patient satisfaction from the provided services in the hospital environment in Oman. This is the first study to be conducted in the country to investigate the satisfaction of the Omani citizens toward health care services. Prior researches from other countries suggested that the health service quality provided to the population of the nation has a significant relationship with patients satisfaction. ${ }^{89}$ As the quality of health care services improves in a country, the patients are going to feel reassured, not only to seek curative services within the country but also services that are preventive in nature. ${ }^{10}$ The assessment of services' quality pose some interesting challenges, which have engaged academics and practitioners in the developed countries for quite some time now. In the past, the health care quality was assessed and defined by clinicians in terms of technical delivery of care. ${ }^{10}$ There was a lack of patient's perspective in determining the quality. Recent literatures show the importance of other factors, including health insurance, administrative policies, and community groups, which may influence the satisfaction of patients toward the provided health care facilities. ${ }^{11}$ Other investigators in this area believe that patient's perspective represents the most important aspect in terms of the quality of health care service delivery. ${ }^{11}$

Out of 1,575 patients who received the questionnaire from all 11 governorates regions of Oman, total 1,164 completed all the questions in the survey (73.9\%). The responses according to the age groups were divided into three categories: less than 25 years (15.5\%), between 25 and 50 years (80.3\%), and more than 50 years (4.2\%) with male to female ratio 1.5:1.0. The distribution of participants in the survey almost reflects the normal population of the governorate, except for Dhofar governorate which has a high population and a low number of participants ( - Table $\mathbf{1}$ ). The highest number of participants were male between the age of 25 and 50 years, which is corresponding with the natural geographic distribution of Omani population (66\% males and $34 \%$ females with a mean age of 36 years $).^{12}$

Participants who received treatments in government or public hospitals were $98 \%$, and those received treatments in local private hospitals were $77.4 \%$. The association between gender, age, marital status, levels of education, and treatments in local private hospitals were statistically significant (- Tables $\mathbf{2}$ and $\mathbf{3}$ ).

Those who received treatments locally in the public or private hospitals preferred to be treated by Omani nurses with 
Table 1 Comparison between population distribution and participation for each governorates

\begin{tabular}{|l|l|l|l|l|}
\hline Governorates $^{\text {a }}$ & Population $^{13}$ & $\%$ & Participant & \% \\
\hline Muscat & 528,327 & 21.1 & 311 & 20.3 \\
\hline Dhofar & 210,984 & 8.4 & 25 & 1.6 \\
\hline Musandam & 28,477 & 1.1 & 63 & 4.1 \\
\hline Al Buraymi & 54,818 & 2.2 & 80 & 5.2 \\
\hline Al Dakhliyah & 343,712 & 13.7 & 210 & 13.7 \\
\hline Al Batinah North & 490,332 & 19.6 & 309 & 20.2 \\
\hline Al Batinah South & 298,649 & 11.9 & 308 & 20.1 \\
\hline Ash Sharqiyah South & 201,783 & 8.1 & 71 & 4.6 \\
\hline Ash Sharqiyah North & 173,113 & 6.9 & 58 & 3.8 \\
\hline Al Dhahirah & 151,308 & 6.0 & 85 & 11 \\
\hline Al Wusta & 23,866 & 1.0 & 1,575 & 5.6 \\
\hline Total & $2,505,369$ & 100 & & 100 \\
\hline
\end{tabular}

astatistic from National Center for Statistic and Information, statistical yearbook 2018.

Table 2 The association between gender and age and receiving treatment in private hospitals

\begin{tabular}{|c|c|c|c|c|c|}
\hline \multirow{2}{*}{$\begin{array}{l}\text { Treated in private } \\
\text { hospital }\end{array}$} & \multicolumn{2}{|l|}{ Gender (\%) } & \multicolumn{3}{|l|}{ Age (\%) } \\
\hline & Male & Female & $<25$ & $25-50$ & $>50$ \\
\hline Yes & $688(79.4)$ & 415 (74) & $264(85)$ & 866 (76.6) & $43(75.4)$ \\
\hline No & $179(20.6)$ & $146(26)$ & 47 (15) & $264(23.4)$ & $14(24.6)$ \\
\hline Total & $867(100)$ & $561(100)$ & $311(100)$ & $1,130(100)$ & $57(100)$ \\
\hline $\mathrm{p}$-value & \multicolumn{2}{|l|}{0.023} & \multicolumn{3}{|l|}{$<0.001$} \\
\hline
\end{tabular}

Table 3 The association between level of education, marital status with receiving treatment in private hospitals

\begin{tabular}{|c|c|c|c|c|c|c|c|c|c|c|}
\hline \multirow{2}{*}{$\begin{array}{l}\text { Treated } \\
\text { in private } \\
\text { hospitals }\end{array}$} & \multicolumn{3}{|c|}{ Marital status (\%) } & \multicolumn{7}{|c|}{ Level of education (\%) } \\
\hline & Single & Married & Divorced & $\begin{array}{l}\text { Less than } \\
\text { high school }\end{array}$ & $\begin{array}{l}\text { High } \\
\text { school }\end{array}$ & $\begin{array}{l}\text { University } \\
\text { student }\end{array}$ & Diploma & Bachelors & Master & PhD \\
\hline Yes & $248(65.1)$ & 848 (81.9) & 7 (63.6) & 34 (66.7) & 346 (70.5) & $133(71.1)$ & $137(85.1)$ & $364(83.1)$ & $69(86.25)$ & $20(100)$ \\
\hline No & $133(34.9)$ & $188(18.1)$ & $4(36.4)$ & 17 (33.3) & 145 (29.5) & $54(28.9)$ & 24 (14.9) & 74 (16.9) & $11(13.75)$ & 0 \\
\hline Total & $381(100)$ & $1,036(100)$ & $11(100)$ & $51(100)$ & $491(100)$ & $187(100)$ & $161(100)$ & $438(100)$ & $80(100)$ & $20(100)$ \\
\hline$p$-value & \multicolumn{3}{|l|}{$<0.001$} & \multicolumn{7}{|l|}{$<0.001$} \\
\hline
\end{tabular}

Table 4 The association between gender and the preference to be treated by Omani doctors

\begin{tabular}{|l|l|l|l|}
\hline \multirow{2}{*}{ Gender } & \multicolumn{3}{|c|}{ Prefer to be treated by Omani doctor } \\
\cline { 2 - 4 } & Yes & No & Total \\
\hline Female & $501(84 \%)$ & $96(16 \%)$ & $597(100 \%)$ \\
\hline Male & $800(88.1)$ & $108(11.9)$ & $908(100 \%)$ \\
\hline Total & 1,301 & 204 & 1,505 \\
\hline$p$-value & 0.015 \\
\hline
\end{tabular}

a percentage of $78 \%$. Also, both males (88.1\%) and females (83.9\%) preferred to be treated by Omani doctors. The association between gender and preference to be treated by Omani doctor was statistically significant ( $p=0.016$; - Table 4 ). The previous studies showed that patients are able to evaluate the doctor's and nurse's skills when they are dealing with patients. ${ }^{14,15}$
The data revealed that most of the population received treatments by the government or local public hospitals more than the private hospitals. This reflects the good quality of health services provided by the government hospitals in Oman. Similar conclusions were drawn by previous researches in Malaysia concluded that countries with nonsatisfactory quality of services in the public hospitals led to greater use of private providers. ${ }^{16}$

On the scale of 0 to 10 (where 0 denotes: poor and 10 denotes: excellent quality of health care), $64.1 \%$ of the participants gave a score of 5 or above for their perception of the quality of general health services in government hospitals (-Fig.1). Most of the participants were unhappy (88\%) regarding to the appointment waiting time (-Fig. 2). The waiting time to get an appointment in tertiary care hospitals according to participants experiences vary between less than 1 month to more than 4 months as shown in 


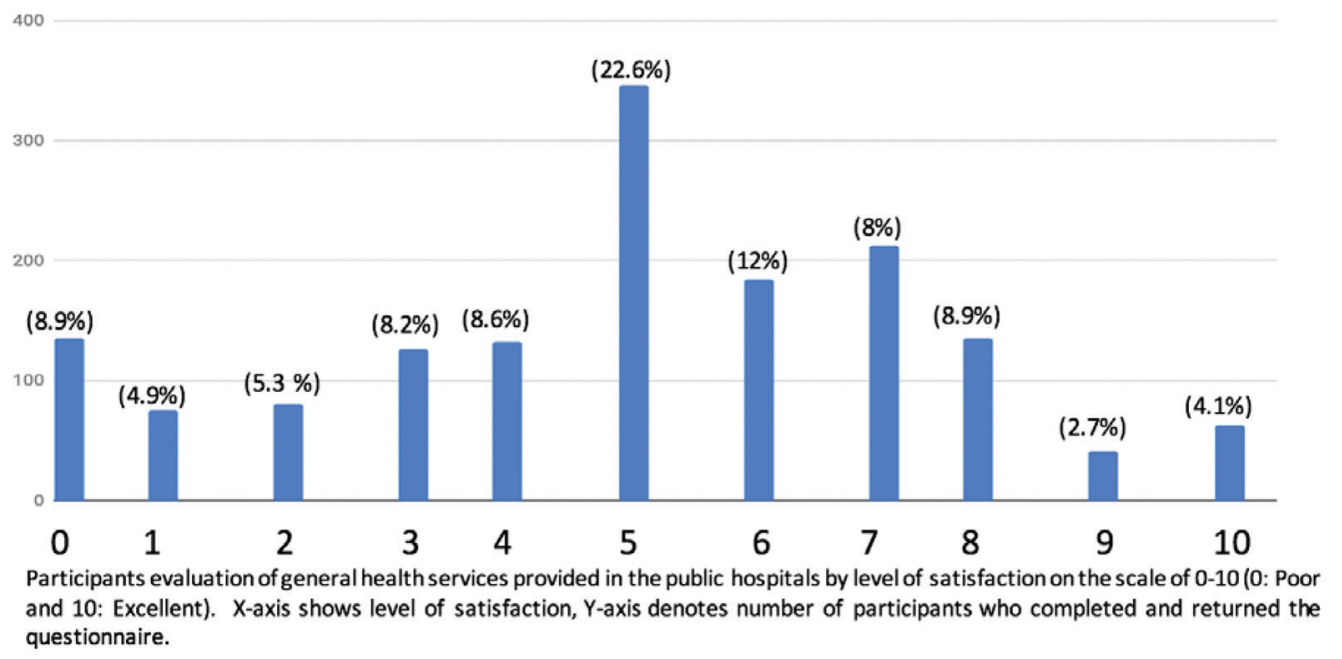

Fig. 1 Participants satisfaction scale of the general health services provided in the public hospitals.

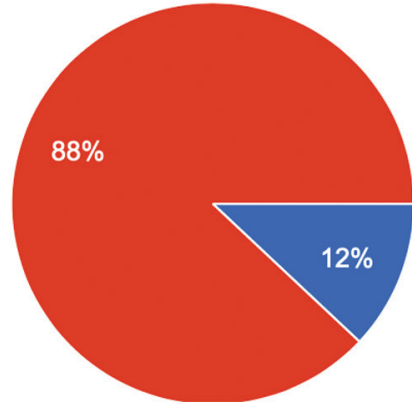

Fig. 2 Patients satisfaction regarding hospital appointments.

Table 5 The average waiting time to get an appointment in tertiary hospitals according to the participants experiences

\begin{tabular}{|l|l|l|}
\hline Duration & Frequency & Percentage \\
\hline Less than 1 mo & 65 & $4 \%$ \\
\hline $1-2$ mo & 350 & $23 \%$ \\
\hline $2-4$ mo & 519 & $35 \%$ \\
\hline More than 4 mo & 535 & $36 \%$ \\
\hline Not mentioned & 35 & $2 \%$ \\
\hline Total & 1,504 & $100 \%$ \\
\hline
\end{tabular}

- Table 5. When compared the data of the present study with that of a previous study, it was observed that there was a relationship between patient satisfaction with waiting time, and the patient in outpatient situation perceives the long waiting time spent to reach the consultant's room as not satisfied and that in turn will affect their behavior accordingly. ${ }^{17}$

In the "travel abroad section," more than a half of the participants preferred to be treated abroad (58.8\%) as compared to those who availed health care local hospitals in Oman (54.5\%). Though not statistically significant, more of the participants traveled abroad for treatments or checkups.
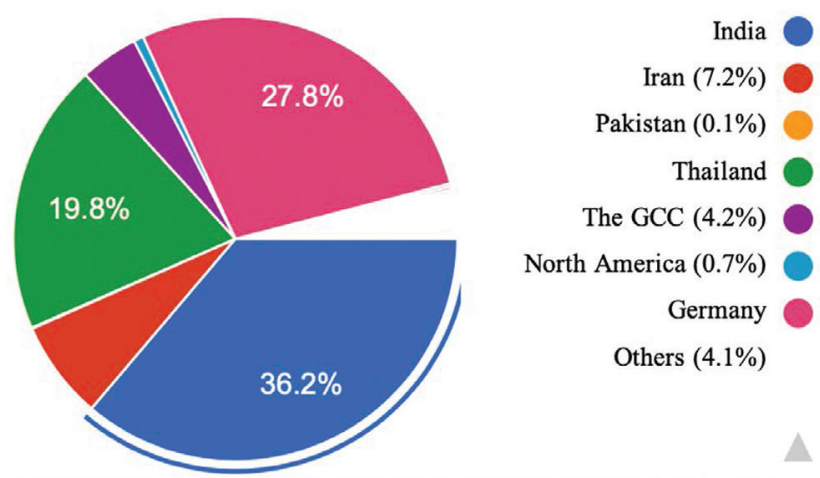

Fig. 3 The preferable destinations for abroad treatment for Omani patients.

The preferable destinations for abroad treatment for Omani patients were hospitals/health care facilities located in India, Germany, Thailand, Iran, the Gulf Cooperation Council countries, and North America ( - Fig. 3). A previous cross-sectional study, which was conducted in the Al Dakhilya region of the Sultanate of Oman, showed that Thailand (50\%) was the first destination followed by India (30.0\%), Iran (10.0\%), Bahrain (7.5\%), and United Arab Emirates 2.5\%. The postulated reason for such a perception is due to the fact that the cost of medical care is less in South Asian countries. Another study done in Saudi Arabia had shown that patients, who traveled abroad for renal transplantation, went to Pakistan (49\%) followed by the Philippines (28\%), Egypt (11\%), and the United States (3.2\%). ${ }^{18}$

Couple of reasons for the Omani patients to travel abroad were revealed in the study including the long waiting time in the local hospitals (52.2\%), lack of confidence in the health services provided in Oman (45\%), high quality of health care abroad (41\%), unavailability of the treatments locally (30.5\%), combining treatments with relaxing holidays (11.5\%), costcompetitive advantages (10\%), and others. In a previous study, Al-Hinai reported that $15 \%$ of the participants did not even seek any medical care locally, but rather traveled 
Table 6 The association between gender, age, and level of education with the efficiency of service received in hospitals

\begin{tabular}{|l|l|l|l|l|l|}
\hline $\begin{array}{l}\text { Services are } \\
\text { provided } \\
\text { efficiently }\end{array}$ & Gender (\%) & Female & Age (\%) & 25-50 y & $>50$ y \\
\cline { 2 - 6 } & Male & $312(53.1)$ & $112(49.6)$ & $698(58.9)$ & $26(43.3)$ \\
\hline Disagree & $524(59.3)$ & $276(46.9)$ & $114(50.4)$ & $487(41.1)$ & $34(56.7)$ \\
\hline Agree & $359(40.7)$ & $588(100)$ & $226(100)$ & $1,185(100)$ & $60(100)$ \\
\hline Total & $883(100)$ & 0.001 & & \\
\hline$p$-value & 0.028 & & & & \\
\hline
\end{tabular}

Table 7 The association between level of education and efficiency of serves received in hospitals

\begin{tabular}{|c|c|c|c|c|c|c|c|}
\hline \multirow{2}{*}{$\begin{array}{l}\text { Services are } \\
\text { provided } \\
\text { efficiently }\end{array}$} & \multicolumn{7}{|c|}{ Level of education (\%) } \\
\hline & $\begin{array}{l}\text { Less than } \\
\text { high school }\end{array}$ & High school & $\begin{array}{l}\text { University } \\
\text { student }\end{array}$ & Diploma & Bachelors & Master & $\mathrm{PhD}$ \\
\hline Disagree & $23(42.6)$ & $297(60)$ & $101(53.2)$ & $96(58.2)$ & $260(56.4)$ & $45(9.3)$ & $14(66.7)$ \\
\hline Agree & $31(57.4)$ & $198(40)$ & $89(46.8)$ & $69(41.8)$ & $201(43.6)$ & $440(90.7)$ & $7(33.3)$ \\
\hline Total & $54(100)$ & $495(100)$ & $190(100)$ & $165(100)$ & $461(100)$ & $485(100)$ & $21(100)$ \\
\hline$p$-value & \multicolumn{7}{|l|}{0.182} \\
\hline
\end{tabular}

Table 8 Association between skilled staff and doctors and doctors communication and information providing to the patient about the participant's condition

\begin{tabular}{|l|l|l|l|}
\hline & $\begin{array}{l}\text { Doctors are willing to } \\
\text { answer any questions }\end{array}$ & $\begin{array}{l}\text { Usually given adequate } \\
\text { information on my } \\
\text { treatment }\end{array}$ & $\begin{array}{l}\text { Usually given adequate } \\
\text { information on my health } \\
\text { condition }\end{array}$ \\
\hline $\begin{array}{l}\text { Hospitals are having skilled } \\
\text { staffs }\end{array}$ & $<0.001$ & $<0.001$ & $<0.001$ \\
\hline
\end{tabular}

Table 9 The association between the overall satisfaction and staff and services provided in the hospitals

\begin{tabular}{|l|l|l|l|l|l|}
\hline & $\begin{array}{l}\text { The nurses } \\
\text { are well } \\
\text { trained }\end{array}$ & $\begin{array}{l}\text { The staffs are } \\
\text { professional }\end{array}$ & $\begin{array}{l}\text { Services are } \\
\text { provided } \\
\text { efficiently }\end{array}$ & $\begin{array}{l}\text { The hospitals are } \\
\text { having skilled } \\
\text { staffs }\end{array}$ & $\begin{array}{l}\text { The doctors are } \\
\text { competent }\end{array}$ \\
\hline $\begin{array}{l}\text { Overall satisfied } \\
\text { with the treat- } \\
\text { ment received at } \\
\text { the hospitals }\end{array}$ & $<0.001$ & $<0.001$ & $<0.001$ & $<0.001$ & $<0.001$ \\
\hline
\end{tabular}

abroad directly without specific explanations. ${ }^{2}$ This study also showed that dissatisfaction with local treatments was reported to be responsible for only $5.9 \%$ cases who travelled to foreign countries for seeking the medical care. ${ }^{2}$ The same study reported that $85 \%$ of the Omani participants traveled abroad to get treatments only, $10 \%$ for both treatments and tourism, and $2.5 \%$ for a health and medical check-up.

Most of the participants agreed that hospitals have skilled staff (68.3\%). However, only $43.1 \%$ of the participants were of the view that the medical care and services were provided efficiently with a statistically significant association with age and the levels of education, but not with gender of participants as showing in - Tables 6 and 7.

- Table 8 shows the significant relationship between the willingness of doctors to answer the patients' questions and providing adequate information on their health conditions/ treatment and between the efficacy of health care. There was a significant relationship between the overall patient's satisfaction from the treatments received at the attending hospital and all of the followings: well-trained nurses, competent doctors, and professional and skilled staff ( $p<0.005$; - Table 9).

The present study is a preliminary investigation and has limited generalization. Further additional researches are needed with further validation of the questionnaire, specifically by including more health/medical care variables. It is important that patient-driven quality standards should be investigated in depth, and addressed more in order to enable service providers to further improve their quality of services.

\section{Conclusion}

In order to achieve a competitive advantage, both government and private hospitals must keep improving their services on a longitudinal and continuous basis to ensure that the quality of service provided are at the maximum level to gain a patient's optimum satisfaction, and to have an impact on patient's future behavioral perceptions. Important inferences of the present study are that the majority of Omanis 
prefer to be treated by Omani doctors. Hospitals need to make new changes in order to decrease appointment's waiting time, as this was found to be one of the most common reasons for population's dissatisfactions.

\section{Conflict of Interest}

None declared.

\section{References}

1 Trinh LN, Fortier MA, Kain ZN. Primer on adult patient satisfaction in perioperative settings. Perioper Med (Lond) 2019;8:11

2 Al-Hinai SS, Al-Busaidi AS, Al-Busaidi IH. Medical tourism abroad: a new challenge to Oman's health system - Al Dakhilya region experience. Sultan Qaboos Univ Med J 2011;11(4): 477-484

3 Bleich SN, Ozaltin E, Murray CK. How does satisfaction with the health-care system relate to patient experience? Bull World Health Organ 2009;87(4):271-278

4 Boissy A, Windover AK, Bokar D, et al. Communication skills training for physicians improves patient satisfaction. J Gen Intern Med 2016;31(7):755-761

5 OCED. OECD Health Statistics 2018. 2018. Available at: http:// www.oecd.org/els/health-systems/health-data.htm. Accessed August 20, 2018

6 The World Health Report 2000 (Health Systems: Improving Performance). WHO Geneva. Available at: https://www.who. int/whr/2000/en/. Accessed 2000

$7 \mathrm{MOH}$ annual health report, Chapter Two: Health Status Indicators, Page No.2 - 3, 2018 Oman. Available at: https:// www.moh.gov.om/en/web/statistics/-/20-60. Accessed 2018

8 Owusu-Frimpong N, Nwankwo S, Dason B. Measuring service quality and patient satisfaction with access to public and private healthcare delivery. Int J Public Sector Management 2010;23(3):203-220

9 Kessler DP, Mylod D. Does patient satisfaction affect patient loyalty.? Int J Health Care Qual Assur 2011;24(4):266-273

10 Andaleeb SS. Determinants of customer satisfaction with hospitals: a managerial model. Int J Health Care Qual Assur Inc Leadersh Health Serv 1998;11(6-7):181-187

11 O'Connor SJ, Shewchuk RM, Carney LW. The great gap. Physicians' perceptions of patient service quality expectations fall short of reality. J Health Care Mark 1994;14(2):32-39

12 “ World Population Prospect- Population Division. “ United Nations, United Nations. Available at: population.un.org/wpp/. Accessed 2019

13 National Center for statistic and information, statistical Yearbook, Page no.79, 2018, Oman. Available at: https:// onlinelibrary.wiley.com/doi/pdf/10.1002/9780470713518. fmatter. Accessed 2018

14 Amin M, Isa Z, Fontaine R. The role of customer satisfaction in enhancing customer loyalty in Malaysian Islamic banks. Serv Ind J 2011;31:1519-1532

15 Manaf NHA. Patient satisfaction in outpatient clinics of Malaysian public hospitals. IIUM Journal of Economics and Management 2006;14(1):81-110

16 Alghamdi SA, Nabi ZG, Alkhafaji DM, et al. Transplant tourism outcome: a single center experience. Transplantation 2010;90(2):184-188

17 Goel S, Sharma D, Singh A. Development and validation of a patient satisfaction questionnaire for outpatients attending health centres in North Indian cities. J Health Serv Res Policy 2014;19(2):85-93

18 Hwang J, Vu GT, Tran BX, et al. Measuring satisfaction with health care services for Vietnamese patients with cardiovascular diseases. PLoS One 2020;15(6):e0235333 